\title{
Association of Carotid Intima Media Thickness with the severity of Coronary Artery Disease in patients undergoing Coronary Artery Bypass Graft Surgery in a tertiary care center
}

\author{
Binayak Gautam ${ }^{1}$, Kunjang Sherpa', Rajan Poudel'1, Pragati Shrestha², Deewakar Sharma², Ram \\ Kishor Sah', Rabi Malla², Arun Maskey², Man Bahadur K.C.' ${ }^{2}$ Sujeeb Rajbhandari².
}

${ }^{1}$ National Academy of Medical Sciences, Mahaboudhha, Kathmandu

${ }^{2}$ Shahid Gangalal National Heart Centre, Bansbari, Kathmandu

Address for correspondence: Binayak Gautam,

Department of Cardiology

National Academy of Medical Sciences Kathmandu, Nepal

E-mail: binayakgautam@gmail.com

ORCID ID NO: 0000-0002-1224-0891

Cite this article as: Gautam B., Sherpa K., Paudel R., et al. Association of Carotid Intima Media Thickness with the severity of Coronary Artery Disease in patients undergoing Coronary Artery Bypass Graft Surgery in a tertiary care center. Nepalese Heart Journal 2019; Vol 16 (2), 35-40

Submission date: $6^{\text {th }}$ July 2019

Accepted date: $18^{\text {th }}$ October 2019

\section{Abstract}

Background and Aims: Atherosclerosis is an inflammatory process involving arteries in various organs. Carotid intima medial thickness (CIMT) can be useful noninvasive tool to detect atherosclerosis for diagnosis of significant cardiovascular disease. We aim to study the association of CIMT with severity of Coronary Artery Disease (CAD).

Methods: This was a cross sectional, observational study conducted in 81 patients with mean age of $59.9 \pm 8.5$ years with a diagnosis of CAD undergoing coronary artery bypass graft (CABG) surgery. The CIMT was measured with B-mode ultrasound in all patients and association with severity of CAD was measured.

Results: The prevalence of increased CIMT in our study group was $31 \%$ and carotid plaque was $69 \%$. Presence of carotid plaque was significantly associated with severe grade CAD stenosis $(\mathrm{t}=4, \mathrm{p}<0.001)$ and presence of Chronic Total Occlusion (CTO) $(\mathrm{p}=0.028)$. There was no significant correlation between mean CIMT and severity of CAD expressed as mean percentage stenosis $(r=0.179, \mathrm{p}=0.11)$ but patients with CTO had higher mean CIMT value than non-CTO group $(0.86 \pm$ $0.21 \mathrm{Vs} 0.73 \pm 0.18 ; \mathrm{p}=0.027)$. We found that diabetic population had greater mean CIMT values than nondiabetic population $(0.82 \pm 0.21$ Vs $0.72 \pm 0.17 ; \mathrm{p}=0.017)$ and higher prevalence of carotid plaque $(\mathrm{p}=0.02)$. Similarly, females were more likely to have increased CIMT than males ( $\mathrm{p}=0.004)$.

Conclusion: We found that increased CIMT was associated with presence of CTO. Presence of carotid plaque was associated with severe grading of CAD and CTO. Carotid ultrasound can be useful noninvasive modality to predict presence of significant CAD.

Keywords: Carotid intima media thickness, Carotid plaque, Coronary artery bypass graft, Coronary artery disease.

DOI: https://doi.org/10.3126/njh.v16i2.26315

\section{Introduction}

Atherosclerosis is a diffuse and progressive pathologic process involving various arterial distribution and has varied clinical presentation that is dependent on the regional circulation involved ${ }^{1,2}$. Atherosclerosis results in formation of complex lesion in the arterial wall called plaques resulting in arterial luminal narrowing. Phenomena like plaque rupture and thrombosis results in the acute clinical complications of myocardial infarction and stroke $\mathrm{s}^{3}$.
Cardiovascular Disease (CVD) remains the leading global cause of death, accounting for 17.3 million deaths per year, a number that is expected to grow to $>23.6$ million by $2030^{4}$. It is also a major health burden in low income countries like Nepal. A hospital-based prevalence study of non-communicable diseases (NCD) in 31 hospitals across the country found that $36.5 \%$ of the admissions were for NCDs, $38 \%$ of which was $\mathrm{CVD}^{5}$. The prevalence of coronary heart disease (CHD) in the male population in eastern Nepal was $5.7 \%{ }^{6}$.

(a) Nepalese Heart Journal. Nepalese Heart Journal retain copyright and works is simultaneously licensed under Creative Commons Attribution License CC - By 4.0 that allows others to share the work with an acknowledge of the work's authorship and initial publication in this journal 
The association between carotid artery disease and coronary artery disease (CAD) has been widely reported in literature. Carotid and coronary artery stenosis share common risk factors and autopsy studies have shown that both share a common pathology ${ }^{7}$ Increase in the carotid intima media thickness (CIMT) is accompanied by yearly risk of $0.7 \%$ to $2.2 \%$ for coronary heart disease, $0.4 \%$ to $1.8 \%$ for stroke and from $1.8 \%$ to $3.2 \%$ for total cardiovascular disease. Increased carotid intimal medial thickness can be used as a surrogate marker of coronary artery disease.

As atherosclerosis is a generalized process, thickening of the intima-media at any local site is generally considered to be an early marker of cardiovascular disease ${ }^{8}$. Most commonly utilized epidemiological tool for this purpose is the measurement of CIMT using ultrasonography as it is readily available, convenient, noninvasive and cost effective ${ }^{9}$. Compared to conventional angiography, studies have found that ultrasonic carotid artery duplex scanning, yields a sensitivity of $99 \%$ and specificity of $84 \%{ }^{10}$. Coexistence of carotid artery diseases with CAD is common and management of such patients is challenging. Patients with carotid artery disease are at the risk of developing perioperative neurological events like stroke. Hence patients undergoing surgical procedure like coronary artery bypass graft (CABG) usually undergo preoperative evaluation of carotid artery ${ }^{11-14}$.

\section{Methods}

This study was hospital based, cross sectional, observational study. It was conducted in Shahid Gangalal National Heart Center, Bansbari, Kathmandu through June 2108 to May 2019 for a period of 1 year. Ethical clearance was formally taken from Institute Review Board, NAMS. The study included 81 patients with CAD undergoing CABG surgery. Patients failing to give consent, those with past history of CABG and carotid endarterectomy were excluded from the study.

Patient undergoing CABG surgery underwent an assessment of bilateral carotid arteries using Philips EPIQ Ultrasound system utilizing B mode and Color Doppler to assess the severity CIMT and associated plaque or any carotid artery stenosis. CIMT was defined by the thickness of intima and media layer which are the innermost hyperechoic and hypoechoic layer in carotid artery wall. Carotid artery luminal stenosis was assessed by color doppler. Mean CIMT values from the far walls of the right and left common carotid arteries (CCAs) (mean-mean) was as per recommendation from American Society of Echocardiography (ASE) ultrasound images of the distal $1 \mathrm{~cm}$ of the far wall of each CCA were obtained to measure CIMT ${ }^{15}$.

Carotid plaque was defined as CIMT $>1.5 \mathrm{~mm}$ or $\geq 50 \%$ of surrounding vessel wall ${ }^{15}$. The high-resolution images of the far wall of the bilateral common carotid artery, internal carotid arteries, and carotid bulbs were obtained to screen for the carotid plaques according to recommendations of the American Society of Echocardiography Carotid Intima-Media Thickness Task Force. The mean CIMT of left and right carotid artery was recorded as mean CIMT. Mean CIMT values of $\leq 0.8 \mathrm{~mm}$ was considered normal and a value $>0.8 \mathrm{~mm}$ was recorded as increased ${ }^{16}$.

As recommended by the Society of Radiologists in the Ultrasound Consensus the degree of stenosis was classified as normal (no stenosis), up to $50 \%$ non-obstructive carotid disease, 50 to $69 \%$ significant stenosis, $>70 \%$ critical or total occlusion.

Severity and grading of coronary artery disease was defined as follows ${ }^{17}$ -

$>50 \%$ stenosis in five major vessels $>2 \mathrm{~mm}$ in diameter is considered coronary artery disease. Left main coronary artery was considered a double vessel disease and other individual arteries a single vessel disease.

Severity of stenosis of an artery was expressed in percentage of luminal obstruction in comparison to arterial diameter in healthy segment and mean percentage stenosis in all the vessels was calculated as a marker of severity of CAD. Presence of chronic total occlusion (CTO) and left main disease (LMD) was recorded and were considered a marker of severe CAD.

\section{Statistical Analysis}

Data analysis was performed using Statistical Package for Social Sciences SPSS (Version 21.0, SPSS Inc, Chicago, IL). Continuous variables were expressed as mean $\pm \mathrm{SD}$ whereas categorical data were expressed in frequency and percentages. Chi square test (or Fischer exact test) was used to analyze the categorical data. Independent sample $\mathrm{T}$ test was performed to analyze the comparison between the continuous variables. A value of $\mathrm{P}<.05$ was taken as statistically significant.

\section{Results}

Table 1: Baseline Characteristics of the Study Subjects

\begin{tabular}{|ll}
\hline Variable & No.(\%) / Mean \pm SD \\
\hline Age (Yr) & $59.9 \pm 8.5$ \\
\hline Elderly (age >60 yrs) & $43(53 \%)$ \\
\hline Male Sex & $62(76 \%)$ \\
\hline Weight $(\mathrm{kg})$ & $63.1 \pm 8.5$ \\
\hline Height $(\mathrm{m})$ & $1.6 \pm 0.09$ \\
\hline BMI $\left(\mathrm{kg} / \mathrm{m}^{2}\right)$ & $24.2 \pm 3.4$ \\
\hline Obesity & $33(41 \%)$ \\
\hline Hypertension & $42(52 \%)$ \\
\hline Diabetes Mellitus & $35(43 \%)$ \\
\hline Dyslipidemia & $25(31 \%)$ \\
\hline Chronic Smoker & $54(64 \%)$ \\
\hline Family History of CVD & $8(10 \%)$ \\
\hline Serum Total Cholesterol (mmol/L) & $3.8 \pm 1.2$ \\
\hline Serum Triglyceride (mmol/L) & $1.5 \pm 0.9$ \\
\hline Serum HDL (mmol/L) & $1.0 \pm 0.2$ \\
\hline Serum LDL (mmol/L) & $2.0 \pm 1.2$ \\
\hline LVEF (\%) & $53.6 \pm 11.4$ \\
\hline Blood Pressure (mmHg) & $123.4 \pm 17.8 / 76.4 \pm 10.7$ \\
\hline Systolic/Diastolic & \\
\hline
\end{tabular}

Systolic / Diastolic

\begin{tabular}{ll} 
Blood sugar (mmol/L) & $7.5 \pm 2.4$ \\
\hline Stroke / TIA & $1(1 \%)$ \\
\hline CAD group - SVD/ DVD/ TVD & $\begin{array}{l}6(7 \%) / 19(24 \%) / 56 \\
(69 \%)\end{array}$ \\
\hline CTO & $19(24 \%)$ \\
LMD & $20(25 \%)$ \\
\hline CAS group - No / Mild/ & $58(72 \%) / 9(11 \%) / 14$ \\
Moderate / Severe & $(17 \%) / 0(0 \%)$ \\
CIMT & \\
\hline Left/ Right/ Mean & $0.76 \pm 0.19 / 0.77 \pm 0.24 /$ \\
& $0.76 \pm 0.19$ \\
Coronary Artery Percentage Stenosis & $83.68 \pm 8.02$ \\
\hline Carotid Plaque & $56(69 \%)$
\end{tabular}


Baseline characteristics of study population

A total of 81 patients who were undergoing $\mathrm{CABG}$ for CAD fulfilling inclusion criteria were included in the study. The study group comprised of 62 males $(76 \%)$ and 19 females (24\%). The mean age of study group was $59.9 \pm 8.5$ yrs with $53 \%$ elderly population. The demographic and clinical characteristics of the study population is summarized in table 1.

Mean CIMT and its association with severity of CAD

Twenty three $(31 \%)$ patients had a high mean CIMT value whereas 56(69\%) patients had a normal mean CIMT value. There was significantly higher mean CIMT in diabetic population than non-diabetic $(0.82 \pm 0.21$ Vs $0.72 \pm 0.17 ; \mathrm{t}=2.34, \mathrm{p}=0.017)$. There was no significant difference in mean CIMT between other groups.

Table 2: Comparison of Variables in two Groups with CIMT cut off of $0.8 \mathrm{~mm}$

\begin{tabular}{|c|c|c|c|}
\hline Variables & $\begin{array}{l}\text { Mean } \\
\text { CIMT } \\
\leq 0.8 \mathrm{~mm} \\
(\mathrm{~N}=56)\end{array}$ & $\begin{array}{l}\text { Mean } \\
\text { CIMT } \\
>0.8 \mathrm{~mm} \\
(\mathrm{~N}=\mathbf{2 5})\end{array}$ & p value \\
\hline Age & $59.6 \pm 9.5$ & $60.72 \pm 6.1$ & 0.54 \\
\hline \multicolumn{4}{|l|}{ Sex } \\
\hline Male/ Female & $48 / 8$ & $14 / 11$ & 0.004 \\
\hline Diabetes Mellitus & 20 & 15 & 0.04 \\
\hline Hypertension & 29 & 13 & 0.98 \\
\hline Dyslipidemia & 15 & 10 & 0.23 \\
\hline Chronic smoker & 36 & 16 & 0.98 \\
\hline $\begin{array}{l}\text { Family History of } \\
\text { CVD }\end{array}$ & 3 & 5 & 0.09 \\
\hline $\begin{array}{l}\text { Serum Total } \\
\text { Cholesterol }(\mathrm{mmol} / \mathrm{L})\end{array}$ & $3.6 \pm 0.7$ & $4.3 \pm 1.9$ & 0.05 \\
\hline $\begin{array}{l}\text { Serum Triglyceride } \\
(\mathrm{mmol} / \mathrm{L})\end{array}$ & $1.48 \pm 0.7$ & $1.7 \pm 1.1$ & 0.34 \\
\hline Serum HDL (mmol/L) & $1.0 \pm 0.19$ & $1.01 \pm 0.31$ & 0.80 \\
\hline Serum LDL (mmol/L) & $1.8 \pm 0.72$ & $2.5 \pm 1.8$ & 0.09 \\
\hline Blood sugar (mmol/L) & $7.5 \pm 2.5$ & $7.5 \pm 2.0$ & 0.92 \\
\hline LVEF (\%) & $55.1 \pm 11.5$ & $50.2 \pm 10.6$ & 0.66 \\
\hline Blood Pressure - SBP & $\begin{array}{l}124.5 \pm \\
19.0 /\end{array}$ & $\begin{array}{l}120.8 \pm \\
14.9 /\end{array}$ & 0.34 \\
\hline DBP & $76.8 \pm 10.6$ & $75.3 \pm 11.0$ & 0.57 \\
\hline $\operatorname{BMI}\left(\mathrm{Kg} / \mathrm{m}^{2}\right)$ & $24.4 \pm 3.5$ & $23.7 \pm 3.4$ & 0.45 \\
\hline Obesity & 23 & 10 & 0.92 \\
\hline \multicolumn{4}{|l|}{ CAD Group - } \\
\hline SVD & 5 & 1 & 0.60 \\
\hline DVD & 14 & 5 & \\
\hline TVD & 37 & 19 & \\
\hline Stroke & 0 & 1 & 0.30 \\
\hline СТO & 11 & 8 & 0.26 \\
\hline LMD & 12 & 8 & 0.40 \\
\hline
\end{tabular}

There was no significant correlation between mean CIMT and mean percentage coronary artery stenosis $(r=0.179, \mathrm{p}=0.11)$. However, patients with CTO in coronary angiography had higher mean CIMT value than non-CTO group $(0.86 \pm 0.21$ Vs $0.73 \pm 0.18 ; \mathrm{t}=2.33, \mathrm{p}=$ 0.027). We found no significant differences in mean CIMT between different CAD groups as per angiography $(0.73 \pm 0.21,0.72 \pm 0.21$ and $0.78 \pm 0.19$ for SVD, DVD and TVD respectively, $\mathrm{p}=0.42$ ). Likewise, there was no significant difference in mean CIMT between Left Main Disease and Non- Left Main disease $(0.80 \pm 0.23$ Vs 0.75 $\pm 0.18 ; \mathrm{t}=0.912, \mathrm{p}=0.37)$.

Fig.1. Box plot Showing Distribution of Mean CIMT in Different CAD Groups.

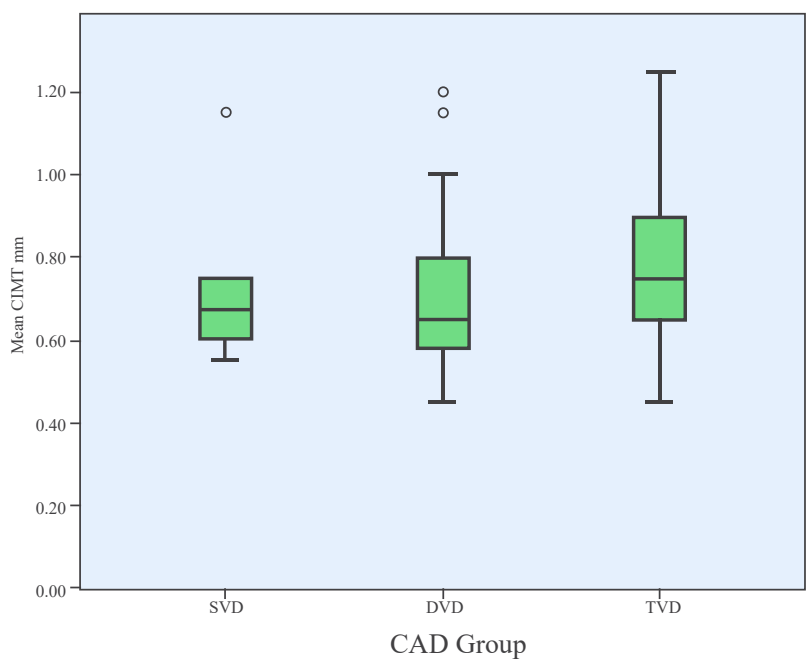

Carotid artery plaque, carotid artery stenosis and its association with CAD

Presence of carotid plaque was significantly associated with severity of CAD expressed as mean percentage stenosis $(t=4, p<0.001)$ (Fig. $2)$. Diabetic patients had higher carotid plaque than non-diabetic patients $(\mathrm{p}=0.02)$. Similarly, presence of plaque in carotid artery was associated with CTO in coronary angiogram $(p=0.028)$. However, presence of carotid plaque was not significantly different within CAD group $(\mathrm{p}=0.78)$. Carotid plaque was not significantly associated with $\operatorname{LMD}(\mathrm{p}=0.07)$.

There was no significant association between presence of carotid artery stenosis and CAD group, LMD or CTO $(\mathrm{p}=0.27, \mathrm{p}=0.14$ and $\mathrm{p}=0.75$ respectively).

Comparison of the patients into those with normal CIMT $(\leq 0.8 \mathrm{~mm})$ and those with high CIMT $(>0.8 \mathrm{~mm})$ showed that diabetes and female sex was significantly associated with thickened CIMT ( $p=0.04$ and $\mathrm{p}=0.004$ respectively) (Table 2 ). However, no other parameters significantly predicted thickened CIMT in these patients. 
Fig. 2. Mean Coronary Artery Stenosis in Patients with and Without Carotid Plaque.

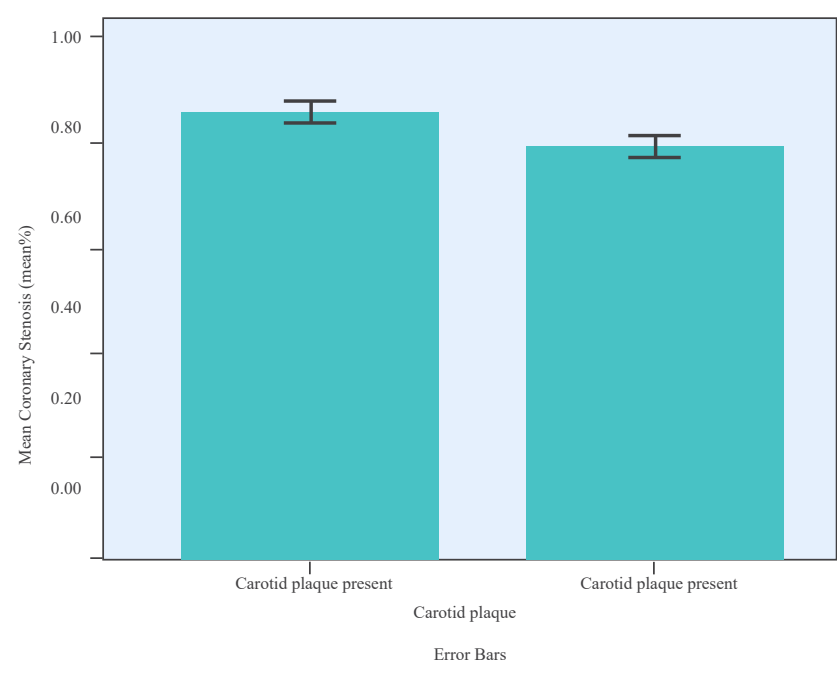

\section{Discussion}

Our study was conducted in a group of patients admitted to the hospital for CABG surgery for coronary revascularization. Majority of the study population had traditional risk factors for CAD. Conventionally, these risk factors are strongly associated with $\mathrm{CAD}^{18}$. We found out that among all risk factors, diabetes was significantly associated with increased CIMT. Diabetes is independent risk factor for atherosclerosis and several studies have shown that it is associated with increased CIMT $^{19,20}$. We found that those with increased CIMT were females rather than males. But sex itself was not associated with differences in mean CIMT. Furthermore, female subjects were less in our study hence a study with sex matched population is required to assess the sex related difference in patients with CAD. Previous studies have concluded that CIMT values are lower in women than in $\operatorname{men}^{21}$.

The prevalence of thickened CIMT in our study population is lower than previous studies ${ }^{22,23}$. We found a significant difference in mean CIMT between CTO and non-CTO group indicating thickened CIMT was associated with complex CAD like CTO. However, we found no significant correlation between mean CIMT and mean percentage coronary stenosis. Similarly, there was no significant difference in mean CIMT values of different CAD groups. This result is in contrast to other studies which have showed a positive correlation between CIMT and severity of $\mathrm{CAD}^{24-26}$. However, other studies have shown no significant association between CIMT and severe CAD given by SYNTAX score ${ }^{27}$. This contrasting results mostly arise due to the fact that other studies were done on patients comparing normal population with CAD group but our study was conducted in patients with CAD undergoing CABG surgery who usually have severe and complex coronary disease.

Prevalence of carotid plaque in our study was higher than studies done in Korea ${ }^{28}$. Previous studies have demonstrated a significant association between prevalence and severity of CAD with carotid artery plaque ${ }^{29-31}$. Our study is in concordance with these previous studies.

We found that the prevalence of carotid artery stenosis in our study was $28 \%$ which was mild to moderate grade stenosis and there was no significant association with severity of CAD. Overall prevalence of CAS in our study was lower than previously reported studies ${ }^{32,33}$.

\section{Limitations}

Our study had some limitations. First, our study enrolled a relatively small sample size from a single center. Second, this study was limited to patients undergoing $\mathrm{CABG}$ hence the results cannot be generalized to asymptomatic population. Furthermore, lower prevalence of thickened CIMT in our study warrants a need for normative data of CIMT in our population so that comparative studies can be conducted in future. Also, influence of inter-observer bias on assessment of CAD severity cannot be ruled out as it was subjective assessment of coronary stenosis.

\section{Conclusion}

We found that mean CIMT did not significantly correlate with mean percentage stenosis of coronary arteries, however, increased CIMT was associated with CTO. Carotid plaque was significantly associated with high grade stenosis and CTO. Diabetic population tend to have higher CIMT than non-diabetic study population. Carotid ultrasonography may aid in non-invasive assessment of atherosclerotic cardiovascular disease.

\section{Sources of funding: None}

\section{Conflict of Interest: None}

\section{References}

1. Libby P, Ridker PM, Hansson GK. Progress and challenges in translating the biology of atherosclerosis. Nature. 2011;473(7347):317-25. https://doi.org/10.1038/nature10146

2. Faxon DP, Fuster V, Libby P, et al. Atherosclerotic Vascular Disease Conference: Writing Group III: pathophysiology. Circulation. 2004;109(21):2617-25.

https://doi.org/10.1161/01.CIR.0000128520.37674.EF

3. Navab M, Berliner JA, Watson AD, et al. The Yin and Yang of oxidation in the development of the fatty streak. A review based on the 1994 George Lyman Duff Memorial Lecture. Arterioscler Thromb Vasc Biol. 1996;16(7):831-42. https://doi.org/10.1161/01.ATV.16.7.831

4. Laslett LJ, Alagona P, Jr., Clark BA, 3rd, et al. The worldwide environment of cardiovascular disease: prevalence, diagnosis, therapy, and policy issues: a report from the American College of Cardiology. J Am Coll Cardiol. 2012;60(25 Suppl):S1-49. https://doi.org/10.1016/j.jacc.2012.11.002

5. Bhandari GP, Neupane S, Ghimire U, Khanal A. Prevalence of Non Communicable Disease in Nepal: Hospital Based Study. Nepal Health Res Council. 2010.

6. Vaidya A, Pokharel PK, Nagesh S, et al. Prevalence of coronary heart disease in the urban adult males of eastern Nepal: a population-based analytical cross-sectional study. Indian Heart J. 2009;61(4):341-7.

7. O'Leary DH, Polak JF, Kronmal RA, et al. Carotid-artery intima and media thickness as a risk factor for myocardial infarction and stroke in older adults. Cardiovascular Health Study Collaborative Research Group. N Engl J Med. 1999;340(1):14-22 https://doi.org/10.1056/NEJM199901073400103 
8. Mohan V, Ravikumar R, Shanthi Rani S, Deepa R. Intimal medial thickness of the carotid artery in South Indian diabetic and non-diabetic subjects: the Chennai Urban Population Study (CUPS). Diabetologia. 2000;43(4):494-9. https://doi.org/10.1007/s001250051334

9. Pignoli P, Tremoli E, Poli A, et al. Intimal plus medial thickness of the arterial wall: a direct measurement with ultrasound imaging. Circulation. 1986;74(6):1399-406. https://doi.org/10.1161/01.CIR.74.6.1399

10. Roederer G, Langlois Y, Chan A, et al. Ultrasonic duplex scanning of extracranial carotid arteries: improved accuracy using new features from the common carotid artery. J Cardiovasc Ultrasonography. 1982;1(4):373-80.

11. O'Connor GT, Plume SK, Olmstead EM, et al. Multivariate prediction of in-hospital mortality associated with coronary artery bypass graft surgery. Northern New England Cardiovascular Disease Study Group. Circulation. 1992;85(6):2110-8.

https://doi.org/10.1161/01.CIR.85.6.2110

12. Rao V, Christakis GT, Weisel RD, et al. Risk factors for stroke following coronary bypass surgery. J Card Surg. 1995;10(4 Suppl):468-74.

https://doi.org/10.1111/j.1540-8191.1995.tb00679.x

13. Reed GL, 3rd, Singer DE, Picard EH, DeSanctis RW. Stroke following coronary-artery bypass surgery. A case-control estimate of the risk from carotid bruits. N Engl J Med. 1988;319(19):1246-50.

https://doi.org/10.1056/NEJM198811103191903

14. Higgins TL, Estafanous FG, Loop FD, et al. Stratification of morbidity and mortality outcome by preoperative risk factors in coronary artery bypass patients. A clinical severity score. JAMA. 1992;267(17):2344-8.

https://doi.org/10.1001/jama.1992.03480170070031

15. Stein JH, Korcarz CE, Hurst RT, et al. Use of carotid ultrasound to identify subclinical vascular disease and evaluate cardiovascular disease risk: a consensus statement from the American Society of Echocardiography Carotid Intima-Media Thickness Task Force endorsed by the Society for Vascular Medicine. J Am Soc Echocardiogr. 2008;21(2):93-111.

https://doi.org/10.1016/j.echo.2007.11.011

16. O'Leary DH, Bots ML. Imaging of atherosclerosis: carotid intima-media thickness. Eur Heart J. 2010;31(14):1682-9. https://doi.org/10.1093/eurheartj/ehq185

17. Scanlon PJ, Faxon DP, Audet A-M, et al. ACC/AHA guidelines for coronary angiography: a report of the American College of Cardiology/American Heart Association Task Force on Practice Guidelines (Committee on Coronary Angiography) developed in collaboration with the Society for Cardiac Angiography and Interventions. Journal of the American College of Cardiology. 1999;33(6):1756-824. https://doi.org/10.1016/S0735-1097(99)00126-6
18. Gerald R. Fowkes F, Housley E, et al. Smoking, lipids, glucose intolerance, and blood pressure as risk factors for peripheral atherosclerosis compared with ischemic heart disease in the Edinburgh Artery Study. Am J Epidemiol. 1992;135(4):331-40.

https://doi.org/10.1093/oxfordjournals.aje.a116294

19. Yamasaki Y, Kawamori R, Matsushima H, et al. Asymptomatic hyperglycaemia is associated with increased intimal plus medial thickness of the carotid artery. Diabetologia. 1995;38(5):585-91. https://doi.org/10.1007/BF00400728

20. Brohall G, Oden A, Fagerberg B. Carotid artery intimamedia thickness in patients with Type 2 diabetes mellitus and impaired glucose tolerance: a systematic review. Diabet Med. 2006;23(6):609-16.

https://doi.org/10.1111/j.1464-5491.2005.01725.x

21. Loboz-Rudnicka M, Jaroch J, Bociaga Z, et al. Impact of cardiovascular risk factors on carotid intima-media thickness: sex differences. Clin Interv Aging. 2016;11:721-31. https://doi.org/10.2147/CIA.S103521

22. Alipour M, Masri D, Mofazzali A, Chitsazan M. Carotid artery intima-media thickness in patients undergoing coronary artery bypass graft surgery. Archives of Cardiovascular Imaging. 2013;1(1):26-30. https://doi.org/10.5812/acvi. 12490

23. Sahadevan M, Chee KH, Tai M-LS. Prevalence of extracranial carotid atherosclerosis in the patients with coronary artery disease in a tertiary hospital in Malaysia. Medicine. 2019;98(15):e15082-e. https://doi.org/10.1097/MD.0000000000015082

24. Latheef K, Praveen M, Vanajakshamma V, Rajasekhar D. Correlation of coronary artery disease angiographic severity with intima-media thickness of carotid artery. Journal of Indian College of Cardiology. 2012;2(4):144-9. https://doi.org/10.1016/j.jicc.2012.09.001

25. Kablak-Ziembicka A, Tracz W, Przewlocki T, et al. Association of increased carotid intima-media thickness with the extent of coronary artery disease. Heart. 2004;90(11):1286-90. https://doi.org/10.1136/hrt.2003.025080

26. Tarzamni MK, Salehi R, Givian F, Farhang S. Association of carotid intima-media thickness with the presence and severity of coronary artery disease. Neurosciences. 2006;4:308-11.

27. Saedi S, Ghadrdoost B, Pouraliakbar H, et al. The association between increased carotid intima-media thickness and SYNTAX Score in coronary artery disease: A single center study. Indian Heart J. 2018;70(5):627-9. https://doi.org/10.1016/j.ihj.2018.01.010

28. Kwon T-G, Kim K-W, Park H-W, et al. Prevalence and Significance of Carotid Plaques in Patients With Coronary Atherosclerosis. Korean Circ J. 2009;39(8):317-21. https://doi.org/10.4070/kcj.2009.39.8.317 
29. Kim JH, Youn HJ, Hong EJ, et al. Clinical Significance of B-Mode Ultrasound of Common Carotid Artery for Prediction of Severity of Coronary Artery Disease: Important Parameters on Hand Measurement. Korean Circ J. 2005;35(6):467-73. https://doi.org/10.4070/kcj.2005.35.6.467

30. Hallerstam S, Larsson PT, Zuber E, Rosfors S. Carotid atherosclerosis is correlated with extent and severity of coronary artery disease evaluated by myocardial perfusion scintigraphy. Angiology. 2004;55(3):281-8. https://doi.org/10.1177/000331970405500307

31. Migliorino D, Mignano A, Evola S, et al. Correlation between carotid atherosclerosis and coronary artery disease: A retrospective study of 1067 patients. Nutrition, Metabolism and Cardiovascular Diseases. 2017;27(1):e28.

https://doi.org/10.1016/j.numecd.2016.11.077

32. Adeoye A, Mullassari A, Ramkumar S, Latchumanadhas K Prevalence of carotid artery disease in candidates undergoing coronary bypass graft seen at Madras Medical Mission. Sahel Medical Journal. 2013;16(2):43-7. https://doi.org/10.4103/1118-8561.115254

33. Akhtar W, Sabih A, Ali A, et al. Carotid artery disease in patients undergoing elective coronary artery bypass surgery. J Coll Physicians Surg Pak. 2009;19(12):759-62. 